\title{
Profissionais da Educação Infantil: Perspectivas sobre Intervenção Precoce
}

\author{
Early Childhood Professionals: \\ Perspectives on Early Intervention
}

\section{Profesionales de la Educación Infantil: Perspectivas sobre la Intervención Temprana}

\author{
Rafaeli Cappellaro-Kobren ${ }^{1}$ \\ iD https://orcid.org/0000-0002-8087-1759 \\ Maria de Fátima Minetto 2 \\ iD https://orcid.org/0000-0002-6796-1610 \\ Wesley Correa ${ }^{3}$ \\ https://orcid.org/0000-0001-7597-6428 \\ Leandro Kruzielski ${ }^{4}$ \\ http://orcid.org/0000-0002-8938-9272
}

Resumo: A demanda pelo atendimento na Educação Infantil (EI) e o avanço das políticas públicas voltadas a crianças com atraso no desenvolvimento alterou as características da população atendida na El. Este artigo procura verificar as concepções dos profissionais da Educação Infantil sobre Intervenção Precoce. A pesquisa teve caráter quantitativo contou com 322 participantes que atuam em Centros de Educação Infantil. O instru-

1 Psicóloga graduada pela Universidade Federal do Paraná (UFPR), Pedagoga graduada pela Universidade Castelo Branco (UCB), com Mestrado pela UFPR na linha de pesquisa em "Cognição, Aprendizagem e Desenvolvimento Humano", Especialista em Educação Especial pelo Instituto Brasileiro de Pós Graduação e Extensão (IBPEX) e Especialista em Gestão Escolar: Orientação e Supervisão pela UCB.

E-mail: rckobren@gmail.com

2 Professora titular da Universidade Federal do Paraná e do Programa de Pós Graduação em Educação da UFPR, na linha de pesquisa Processos Psicológicos em Contextos Educacionais.

E-mail: fa.minetto@gmail.com

3 Psicólogo na área clínica, educacional e social, Docente para cursos de Graduação, Pós-Graduação e Formação Continuada. Psicólogo clínico na cooperativa de médicos Unimed Curitiba.

E-mail: wesleycorrea.psicologo@gmail.com

4 Professor Adjunto A do Departamento de Teorias e Fundamentos da Educação da Universidade Federal do Paraná.

E-mail: leandro.psi@gmail.com 
mento utilizado foi o "Questionário das concepções dos profissionais da Educação Infantil sobre Intervenção Precoce", elaborado pela pesquisadora e colaboradores. A coleta dos dados ocorreu online. Os resultados apontaram que as concepções dos profissionais da Educação Infantil sobre IP são variadas, desde a centrada na criança, visando à superação de déficits a concepções pautadas na perspectiva bioecológica do desenvolvimento. $O$ contexto familiar apresenta-se como um desafio para a melhoria da comunicação e parceria entre as famílias de crianças com atraso e os Centros de Educação Infantil.

Palavras-chave: Intervenção Precoce. Concepção de profissionais da educação. Perspectiva bioecológica do desenvolvimento humano. Educação Infantil.

\begin{abstract}
The growing demand for care in Early Childhood Education (EI) and the advancement of public policies aimed at children with developmental delays change the characteristics of the population served in relation to the social, cultural and educational delineation, as well as the demands related to El. Therefore, this article seeks to verify the conceptions of early childhood education professionals about El. The research has a predominantly quantitative character and included $322 \mathrm{El}$ professionals, they answered the "Questionnaire on the Conceptions of Early Childhood Education Professionals", an instrument developed by the researcher and collaborators. Data collection took place online. The results showed that the conceptions of the professionals of the Early Education are varied, from the centered in the child aiming at the overcoming of deficits, to conceptions centered in the family or systems. The family context presents itself as a challenge to improve communication and partnership with the Centers for Early Childhood Education.
\end{abstract}

Keywords: Early intervention. Conceptions of education professionals. Bioecology human development. Childhood education.

Resumen: La demanda por la atención en la Educación Infantil (EI) y el avance de las políticas públicas dirigidas a niños con retraso en el desarrollo han alterado las características de la población atendida en la El. Este artículo busca verificar las concepciones de los profesionales de la Educación Infantil sobre Intervención Temprana. La encuesta tuvo carácter cuantitativo contó con 322 participantes que actúan en Centros de Educación Infantil. El instrumento utilizado fue "Cuestionario de las concepciones de los profesionales de la Educación Infantil sobre Intervención Temprana", elaborado por la investigadora y colaboradores. La recolección de datos se produjo en línea. Los resultados apuntaron que las concepciones de los profesionales de la Educación Infantil sobre IP son variadas, desde la centrada en el niño, visando la superación de déficits, hasta las pautadas en la perspectiva bioecológica del desarrollo. El contexto familiar se presenta como un desafío para la mejora de la comunicación y asociación entre las familias de niños con retraso y los Centros de Educación Infantil. Palabras clave: Intervención temprana. Concepción de profesionales de la educación. Perspectiva bioecológica del desarrollo humano. Educación Infantil.

\title{
1 INTRODUÇÃO
}

Nas últimas décadas ocorreram mudanças nas políticas públicas no sentido de acoIher e promover as demandas relacionadas ao atendimento às crianças pequenas. Inúmeros programas de Intervenção Precoce foram desenvolvidos. (UNESCO, 1990; KARANEZI, RAPTI, 2015).

No Brasil a Lei de Diretrizes e Bases da Educação (LDB), Lei n. 9394/96, insere a Educação Infantil para crianças de zero a seis anos como primeira etapa de ensino, devendo ser ofertada em creches e pré-escolas, e propõe a sistematização dos serviços educacionais especializados oferecidos a crianças na faixa etária de zero a três anos (BRASIL, 1996). O Ministério da Educação publicou o documento Diretrizes Educacionais sobre Esti- 
mulação Precoce - Série Diretrizes, com a finalidade de fundamentar a implantação e atualização da Estimulação Precoce no Brasil (BRASIL, 1995). O Plano Nacional de Educação define metas a serem atingidas até 2020 a fim de nortear as políticas e ações de ensino no país. Entre essas metas consta a obrigatoriedade do ensino para crianças a partir de quatro anos, a ampliação da educação integral e a organização de programas de estimulação precoce "em parceria com as áreas de saúde e assistência [...] para as crianças com necessidades educacionais especiais, em instituições especializadas ou regulares de Educação Infantil, especialmente creches" (2014). Isso impacta num movimento de direito à educação e inserção de crianças com deficiência e atrasos no desenvolvimento no ensino comum e aproxima a Educação Infantil do ensino especializado. A Educação Infantil se estabelece com crescente demanda e mudanças no perfil do público atendido, e fica evidente a necessidade de preparação dos professores e reorganização desse serviço para um atendimento condizente com essa nova realidade educacional (BEYER, 2005, COSTA, 2012).

No âmbito internacional a preocupação com a primeira infância envolve diferentes programas de intervenção que, desde a década de 90, vêm modificando sua abordagem. Políticas públicas pautadas em taxas de mortalidade infantil passam a ser norteadas por taxa de sobrevivência infantil, e o desenvolvimento é visto como dependente de diversas modalidades de intervenção (nutrição, saúde, educação, família), não se restringindo à ação direta com a criança. A preocupação com o desenvolvimento não considera apenas o crescimento pautado em padrões da saúde, e sim avaliado conforme os parâmetros da própria criança, vislumbrando-se a possibilidade de seu acompanhamento, uma vez que crescimento e desenvolvimento são interdependentes, mas não coincidentes. A ação não visa apenas à sobrevivência da criança, mas a qualidade das condições de vida para o desenvolvimento, este definido como um processo de mudança através do qual a criança aprende a dominar níveis progressivamente mais complexos de ação, pensamento, emoção e interação social (UNESCO, 1990; MINETTO, CREPALDI, 2017): "... o desenvolvimento da criança é visto como o produto das contínuas interações dinâmicas da criança e a experiência proporcionada por sua família e o contexto social" (SAMEROFF, OLSON, 2011).

As investigações no campo da psicologia, da neurologia e do desenvolvimento foram alterando a evolução dos modelos e práticas na IP. Os primeiros programas surgiram nos Estados Unidos na década de 60 e visavam à adaptação da criança em risco devido à pobreza do ambiente familiar. Na década de 70 esses programas recebem grande influência da psicologia comportamental, e os pais são orientados por profissionais quanto à melhor forma de interação com o filho. Nos anos 80 há uma tendência ao trabalho individualizado e a família é convocada a participar ativamente da estimulação. Nos anos 90 é reconhecida a 
importância da família em todo o processo de intervenção assim como a cooperação entre a equipe técnica terapêutica e a família (CARVALHO, 2008). O trabalho atual na IP requer uma transposição de leitura da realidade puramente médica com diagnóstico baseado na etiologia (genética, biológica ou neurológica), ou voltado à causação social ou sindrômica. Implica uma compreensão de outras dimensões da realidade, a passagem para uma abordagem diagnóstica funcional. A IP envolve diferentes profissionais e necessita de uma ação complementar e articulada entre os profissionais envolvidos (FRANCO, MELO, APOLÓNIO, 2012; FRANCO, 2016).

No Brasil, esses programas chegaram dez anos depois de iniciarem nos Estados Unidos e evoluíram em fases similares à americana. Porém, em muitos países ainda há programas centrados na criança e na supressão de deficiências e têm o objetivo de desenvolver habilidades faltantes, que geralmente são estimuladas por terapeutas de áreas específicas da saúde (FRANCO, 2015; FERNANDEZ, 2016; MARINI, LOURENÇO, BARBA, 2017).

A perspectiva bioecológica contribui para um olhar sistêmico sobre o desenvolvimento humano, tornando o conceito de Intervenção Precoce mais amplo, definido como um conjunto das intervenções, voltadas a crianças de 0-6 anos, à família e ao contexto, que tem por objetivo responder às necessidades apresentadas pelas crianças com perturbações no desenvolvimento ou que as estão em risco de às vir apresentar. Devem ser planejadas por uma equipe interdisciplinar ou transdisciplinar. (GAT, 2008)

Em consonância com o paradigma bioecológico encontra-se o modelo transacional, Sameroff e Chandler (1975) verificaram que muitos estudos sobre o desenvolvimento se referiam às características físicas e comportamentais exclusivas da criança e sua interação com o ambiente e que essas ações impactavam seu desenvolvimento. Consideraram os modelos de análise do desenvolvimento centrados unicamente nas características do indivíduo e no impacto sobre suas famílias como insuficientes para caracterizar e favorecer o desenvolvimento humano. Em seu artigo A Unified Theory of Development: A Dialectic Integration of Nature and Nurture (2000), Sameroff e Fiese discutem sobre os aspectos biológicos e sociais que influenciam o comportamento.

The dialectical perspective on nature and nurture is that they mutually constitute each other. There is a unity of opposites in that development will not occur without both, and there is an interpenetration of opposites in that one's nature changes one's nurture and conversely one's nurture changes one's nature, as captured in current transactional models. Moreover, and most salient, without the one, the other would not exist. (Sameroff, Fiese, 2000, p. 9) 
Essas reflexões deram início ao modelo transacional, que se caracteriza pelas contínuas transformações ou transações decorrentes entre o indivíduo e o meio no transcorrer do tempo. Esse modelo apresenta uma visão dinâmica das variáveis da criança e do ambiente tanto em processos internos quanto externos, e implica em mudanças, adaptações e novos padrões experienciais. O comportamento da criança ao longo do tempo é visto como um produto das transações entre o fenótipo, a pessoa, o environtype, a fonte de experiência externa, e o genótipo, que é a fonte de organização biológica. O modelo Transacional enfatiza também a contribuição de características físicas e comportamentais exclusivas da criança para o seu próprio desenvolvimento, em particular sua interação com o ambiente, pois o ambiente não influi igualmente sobre todas as crianças, ou seja, a criança não é simples receptora de influências ambientais (SAMEROFF, 2009).

Essa teoria unificada do desenvolvimento humano pressupõe mudanças pessoais, contextuais, representacionais e regulacionais. Nessa perspectiva, o ambiente deve ser compreendido de forma ampla, envolvendo a família, a comunidade, fatores culturais e sociais. O environtype diz respeito a um conjunto organizado de subsistemas que interagem entre si e com a criança. Inclui uma estrutura organizacional que capta a qualidade da influência do ambiente ao longo da vida. No contexto do environtype existe uma organização social que opera através de padrões familiares e culturais de socialização, regulando a maneira como o indivíduo se relaciona em sociedade. Dessa forma, as regulações do desenvolvimento cognitivo e socioemocional que ocorrem dentro de cada subsistema do environtype são permeadas por códigos, como o código cultural, o código familiar ou o código individual, com a finalidade de permitir à criança desenvolver funções dentro da sociedade (SAMEROFF, 2009).

As regulações vinculadas ao nível do environtype podem ser compreendidas como:

- Macrorregulações (presentes no código cultural): intencionais, são grandes mudanças na experiência, que se estendem durante longos períodos de tempo.

- Minirregulações (presentes no código familiar): atividades de cuidado que ocorrem diariamente e incluem vestir-se, alimentar-se ou disciplinar-se.

- Microrregulações (presentes no código individual): padrões quase automáticos de interações momentâneas. Nessa perspectiva, o impacto sobre o desenvolvimento infantil se dá muito mais pela quantidade de variáveis às quais a criança é exposta do que pela natureza dessas variáveis (Sameroff, Fiese, 2000).

Essas contribuições, juntamente com a incorporação dos conceitos do modelo ecológico, evidenciaram a importância de ampliar a atenção para além das necessidades biop- 
sicológicas das crianças, ou seja, o conceito de risco e proteção na infância é ampliado para além de dimensões intraindividuais ou intrafamiliares. Maior atenção é atribuída ao estudo do impacto de fatores ambientais sobre o desenvolvimento, abordando-se desde as práticas parentais pertencentes aos contextos imediatos até as características econômicas e comunitárias (SERRANO, 2007).

A partir disso as estratégias que passaram a delinear os objetivos da IP basearam-se em três categorias: remediação, redefinição e reeducação. A remediação volta-se às necessidades da criança, refere-se ao biológico ou socioemocional e tem como objetivo mudar a forma de interação da criança com os pais; a redefinição centra-se na interpretação que os pais possuem sobre o comportamento da criança e busca a promoção de interações positivas; a reeducação diz respeito à forma como os pais agem com a criança e tem como objetivo fornecer suporte para que respondam adequadamente às necessidades de cuidado da criança. A Intervenção Precoce utiliza-se de estratégias de ação que consideram as necessidades de cada caso e devem estar alinhadas com os recursos e características individuais das famílias e das crianças (SAMEROFF, FIESE, 2000).

Na mesma lógica a perspectiva bioecológica do desenvolvimento humano coloca que o desenvolvimento não depende só do cuidado das relações diretas ou de processos intrapsíquicos, mas da influência das relações dos diferentes contextos que envolvem a pessoa, e depende dos níveis de interação dos mais próximos aos mais distantes (BRONFENBRENNER, 2011; GURALNICK, 2011; FRANCO, 2015; MINETTO, CREPALDI, 2017). Distancia-se da visão analítica e especializada da pessoa, do trabalho enfatizando áreas específicas, seja motor, cognitivo ou de linguagem. A Intervenção Precoce tem como objetivo o máximo desenvolvimento da criança, da família e do contexto (SANCHEZ-CARAVACA, GIL, 2012; FRANCO, 2015).

Nessa perspectiva considera-se importante para a promoção do desenvolvimento ações que antecipem os problemas que possam vir a ocorrer. A prevenção é a possibilidade de intervir antes da instalação de um atraso significativo no desenvolvimento, que pode ser de caráter primário, secundário e terciário. A prevenção primária se caracteriza pela necessidade de otimizar ou manter os níveis de saúde e bem-estar alcançados pela população infantil. Pérez-Ramos (1990) enfatiza a importância de ações divulgadoras e promocionais para fortalecer o processo evolutivo integral na primeira infância. A prevenção secundária envolve a atuação com crianças que, sob o impacto dos fatores de risco, podem apresentar distúrbios no seu desenvolvimento (PEREZ-RAMOS, 1990). A prevenção terciária configura-se em ações dirigidas às crianças afetadas em diferentes áreas, como cognitiva, visual, auditiva, motora e emocional, com a finalidade de atenuar 
os efeitos de atrasos já instalados. A prevenção permite evitar, controlar ou minimizar o declínio no desenvolvimento da criança (prevenção primaria), atenuar ou eliminar a suscetibilidade orgânica ou psicológica das crianças (prevenção secundária). A essência da Intervenção Precoce envolve essas bases de atendimento, que se caracterizam como emergenciais, propõe um processo de desenvolvimento da infância mais adequado e seguro (PEREZ-RAMOS, 1996).

Partindo desta perspectiva de desenvolvimento humano, Guralnick (2011, 2015, 2016) propõe uma abordagem que tem como objetivo compreender os mecanismos envolvidos na promoção do desenvolvimento da criança no contexto da IP. A abordagem de desenvolvimento de sistemas (DSA) envolve a atenção a três níveis relacionados.

O primeiro nível refere-se a como a criança utiliza seus recursos e processos organizacionais para expandir suas competências e atingir seus objetivos, são os recursos desenvolvimentais e envolvem a linguagem, cognição, áreas sensório-perceptiva, motora e sócio emocional. Um segundo aspecto dentro do primeiro nível diz respeito aos processos organizacionais: 1) Funções executivas: organização dos processos que visam orientações para metas. 2) Metacognição: consciência da tarefa para resolução de problemas. 3) Cognição social: relação interpessoal e respostas pró-sociais. 4) Motivação: persistência na execução de tarefas. 5) Regulação da emoção: avaliação das experiências emocionais e geração de estratégias para manter a orientação para metas $O$ terceiro aspecto refere-se às competências sociais e cognitivas, à capacidade de interação e utilização dos recursos anteriores. (GURALNICK, 2011).

Nessa perspectiva da IP, é importante que se construa um perfil dos recursos de desenvolvimento da criança e dos processos organizacionais para traçar as metas de trabalho. O segundo nível refere-se às influências ambientais, aos padrões familiares de interação entre pais e filhos, que promovem a competência social e cognitiva. Compreende: 1) Sensibilidade: a capacidade de resposta dos pais frente às demandas dos filhos. 2) Conexão sócio emocional: estabelecimento de ligações afetivas com os pais e com outras crianças. 3) Parceria instrucional: capacidade e disponibilidade dos pais de serem parceiros na aprendizagem dos filhos. A partir desses pilares se edifica a forma como os pais apresentam o mundo para a criança e a ajudam a construir sua rede social.

O terceiro nível envolve os recursos familiares, as características pessoais dos pais (saúde física, mental e intelectual), como reagem ou estão envolvidos em estressores ambientais, pois estes podem romper os padrões familiares de interação. Neste nível os recursos financeiros são considerados fatores importantes na análise de estressores. (GURALNICK 2011, 2015). Essa abordagem é sistematizada na figura 1. 
Figura 1 - Abordagem de desenvolvimento de sistemas

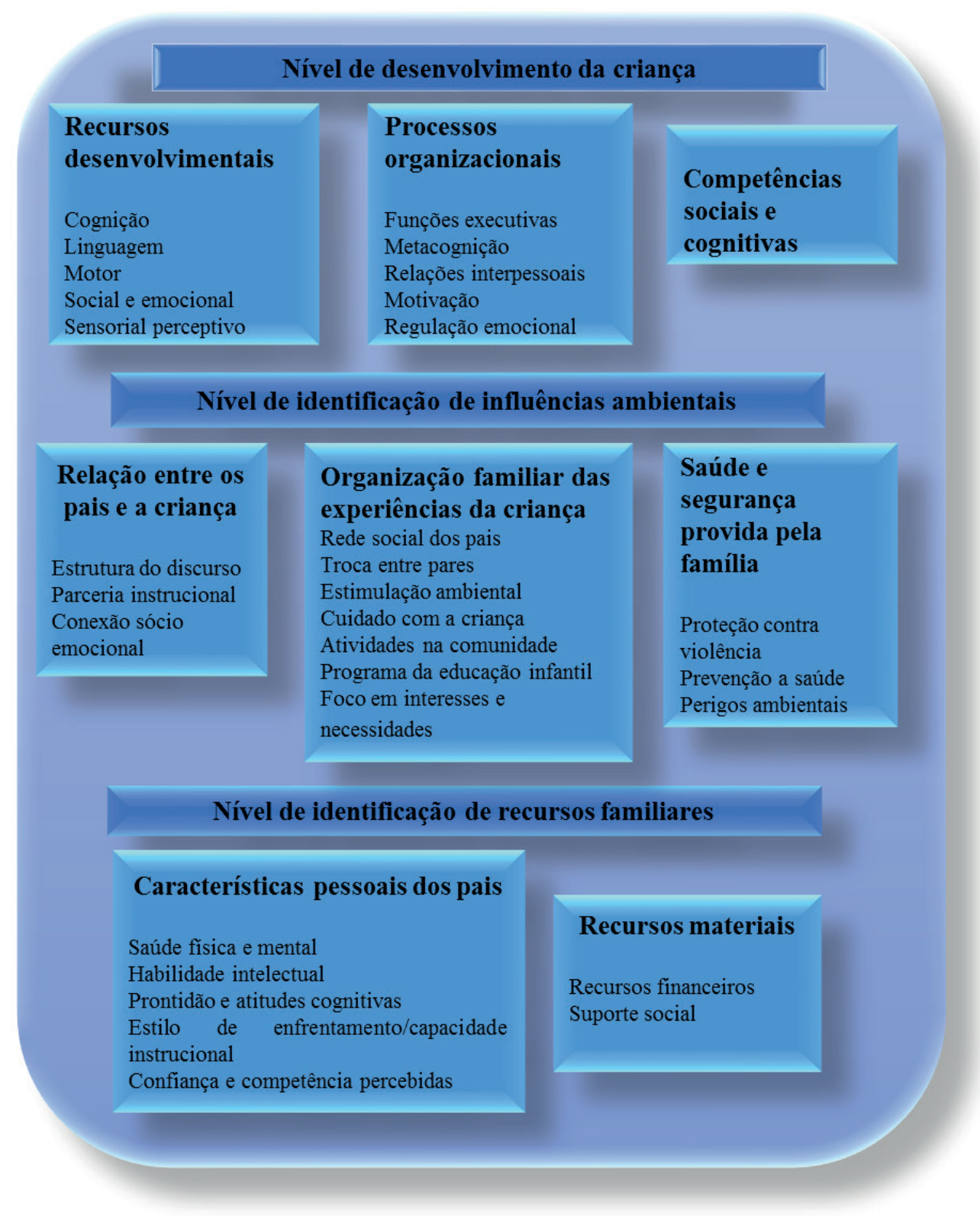

Fonte: Tradução nossa, adaptado de Why early interventions Works :a systems perspective. Guralnick,2011. Infants \& Young Children, 24, 6-28.

Os padrões familiares de interação podem ser afetados com o nascimento de uma criança com deficiência ou com a notícia de um diagnóstico inesperado. As famílias se preparam para a chegada de um filho perfeito, e a quebra desse ideal deflagra uma crise, que exigirá mudanças para um novo e diferente padrão de interação. Essa crise comumente transcorre em etapas semelhantes às do luto (elaboração de algo perdido), nesse caso 
do filho, da criança idealizada. Ao saberem da deficiência dos filhos, inicialmente os pais passam por um estado de desconforto emocional que pode se caracterizar por tristeza, depressão, revolta. Essa fase pode ser superada com a elaboração do luto. Os pais que não conseguem transpor essa fase e ficam ligados à criança idealizada não se vinculam emocionalmente com seus filhos reais, estabelecendo um padrão disfuncional de relacionamento (MINETTO, 2010; FRANCO, 2015). À IP cabe fornecer o apoio emocional aos pais para superarem essa fase de luto e idealizarem novamente o filho real Franco (2015) preconiza que isso acontece quando três dimensões são construídas: perceber a beleza de seu filho, não o esconder da sociedade, pensar sobre suas capacidades. A criança poderá ter déficit em algumas coisas, mas habilidades em outras e, finalmente, conseguir vislumbrar um futuro para essa criança com o desejo de vê-la da forma mais autônoma possível e não como uma eterna criança. A promoção do desenvolvimento ocorre quando a IP consegue identificar e interferir nos estressores e estabelecer ou restaurar para um meIhor nível os padrões familiares de interação (MINETTO, CREPALDI, BERMUDEZ, 2017).

Na visão de sistemas a Educação Infantil deve considerar todos os aspectos de recursos da família para compreender seus padrões de funcionamento. Aspectos que podem funcionar como fatores de risco e proteção, e as crianças tornarem-se vulneráveis ou resilientes. (GURALNICK, 2011). Quando a IP consegue identificar e interferir nos estressores ambientais, promovendo uma rede de apoio, e estabelecer ou restaurar para um melhor nível possível os padrões familiares de interação, a consequência é favorável ao desenvolvimento.

Segundo Dunst e Hawks (2015) e Aleixo (2016) os programas centrados na família e na primeira infância buscam engajar as famílias não envolvidas com a educação dos filhos e relacionar suas práticas com o desejo, prioridades e preocupações da própria família. Nesses programas são usadas estruturas conceituais e procedimentos de mensuração. No Brasil essa prática não é comum, pois há uma carência de testes padronizados para o diagnóstico do desenvolvimento, postergando-se ações que poderiam ser derivadas desse diagnóstico (DORNELAS, DUARTE, MAGALHÃES, 2015).

Conforme a perspectiva bioecológica, a Educação Infantil representa um microssistema de grande influência no desenvolvimento humano e pode criar oportunidades de identificação e resposta efetiva aos problemas desenvolvimentais (BRONFRENBRENNER, 2011, SOEJIMA, 2008, 2012). Os Centros de Educação Infantil são locais de observação do comportamento e desempenho da criança, podendo identificar e possibilitar a prevenção e a intervenção nas crianças consideradas de risco MARTINS, FORMIGA, VIEIRA, LINHARES, 2015, VALIATTI, 2015). 
Verificar a concepção dos profissionais que atuam na El sobre Intervenção Precoce torna-se imprescindível para ações assertivas nessa área, uma vez que a definição de concepção se refere a "sistemas complexos de explicação" ou rede de ideias e conceitos que informam como as pessoas pensam e agem diante de determinada situação. Num sentido mais específico, envolve um processo de construção de conceitos. As concepções possuem ideias gerais e podem ser consideradas a partir de seu uso e aplicação, por isso tornam-se instrumentos de trabalho para compreensão de diferentes objetos (GUIMARÃES, 2010).

Um dos pressupostos principais sobre o qual se assenta a investigação realizada na área do pensamento do professor é que suas concepções influenciam fortemente a prática que desenvolve, embora a natureza dessa influência não seja totalmente conhecida. Compreender essas concepções é essencial para entender a atuação dos professores e poder intervir na melhoria da sua formação e da sua prática pedagógica (GUIMARÃES, 2010; MATOS, JARDILINO, 2016).

\section{MÉTODO}

A pesquisa possui caráter quantitativo, alcance inicial exploratório e descritivo, corte transversal e amostra aleatória (SELLTIZ, WRIGHTSMAN, COOK, SAMPIERI, COLLADO, LUCIO, 2013).

\section{PARTICIPANTES}

Os participantes selecionados em uma amostra por conveniência constituem-se de 322 profissionais dos Centros de Educação Infantil (CMEls), coordenadores técnico pedagógicos, diretores, equipes de pedagogos dos Núcleos Regionais de Educação e da Secretaria Municipal de Educação de uma capital da região Sul do país, Região Metropolitana e outras cidades do Estado atuantes e não atuantes com crianças que podem ou não apresentar atraso no desenvolvimento.

\section{INSTRUMENTOS}

Como instrumento para coleta de dados, optou-se por um questionário contendo 31 questões, que se dividem entre questões fechadas $(n=24)$, abertas $(n=03)$ e questões combinadas $(n=04)$. As questões fechadas foram constituídas de 13 em escala Likert, 2 dicotômicas e 9 com múltiplas respostas. Esse questionário denominou-se: "Questionário das concepções dos profissionais da Educação Infantil sobre Intervenção Precoce". Foi 
elaborado pela pesquisadora e colaboradores com base em estudos desenvolvidos por Guralnick (2011, 2015), Franco (2015), Franco e Apolônio (2011), bem como em pesquisas recentes em Intervenção Precoce. O teste de confiabilidade a de Cronbach foi realizado com a finalidade de averiguar a consistência interna dos itens do questionário e apresentou bom índice. O questionário divide-se em 4 eixos, que condensam questões de temas afins. Eixo I - Identificação profissional: teve por objetivo caracterizar os participantes por meio de variáveis independentes, como idade, estado civil, formação e tempo de profissão. É constituído por questões fechadas $(n=13)$ e questões combinadas (abertas e fechadas) $(n=4)$. Eixo II - Percepção sobre atrasos no desenvolvimento: concentrada a descrição da história profissional, o envolvimento com a profissão, os contatos com crianças que apresentam atraso no desenvolvimento, a capacidade de identificação de crianças com atraso, a comunicação e as relações interpessoais no ambiente profissional para organização de planos de ação frente a essas crianças. Compreende cinco questões, sendo uma com resposta múltipla, e quatro questões fechadas em escala Likert: nunca $(=1)$; quase nunca $(=2)$; às vezes ( $=3$ ), quase sempre ( $=4)$; sempre $(=5)$. A consistência interna ( $\alpha$ de Cronbach) desta seção é de 0,893. Eixo III - Concepções sobre Intervenção Precoce: contempla questões sobre concepções verdadeiras e falsas levantadas na revisão de literatura e em itens extraídos de estudos de Guralnick (2011), Franco (2015) além da adaptação de perguntas do questionário utilizado na pesquisa de Franco e Apolonio (2011).

A estruturação das questões que investigam concepções sobre IP compreende duas subseções. Na primeira, os participantes responderam a uma questão de respostas múltiplas com 15 sentenças, das quais em uma o participante declara não saber bem o que é IP; 11 sentenças contêm afirmativas sobre concepções verdadeiras e 3 sobre concepções falsas. Foi avaliado o índice de confiabilidade desse questionário e obtiveram-se bons resultados. Neste eixo, apenas as concepções falsas precisariam ser complementadas com mais questões para alcançarem um índice mais elevado de consistência interna. As verdadeiras apresentam um índice de confiabilidade ( $\alpha$ de Cronbach) $\alpha$ 0,854 e as falsas $\alpha$ 0,579. A segunda subseção apresenta duas questões dicotômicas sobre participação em curso sobre Intervenção Precoce. A terceira subseção teve 11 questões em escala Likert: nunca $(=0)$; quase nunca $(=1)$; às vezes $(=2)$; quase sempre $(=3)$; sempre $(=4)$, com o objetivo de compreender as concepções sobre pessoas, profissionais e contextos na IP. Eixo IV - Ações diante da criança com atrasos no desenvolvimento: foi utilizada apenas a questão 4.6, que diz respeito às ações dos profissionais da El diante das crianças com atraso no desenvolvimento. 


\section{PROCEDIMENTOS}

\subsection{Coleta de dados}

A pesquisa intercorreu em ambiente virtual (por meio de formulário eletrônico) em plataforma Learning Management System Moodle, e foi realizada em local de livre escolha do participante com acesso à internet. Foi feito contato com o Departamento de Educação Infantil da Secretaria Municipal de Educação da capital em questão e envolveu o Departamento de Educação Infantil, a Coordenadoria de Atendimento às Necessidades Especiais (CANE) e a Equipe responsável pela Saúde dentro desse Departamento. A divulgação almejou que todos os profissionais tivessem acesso ao questionário em formulário online e que os interessados pudessem participar da pesquisa respondendo a esse instrumento. Foi ofertado um curso a quem respondesse o questionário, inicialmente proposto para os profissionais da Educação Infantil da capital, porém houve divulgação dos próprios participantes e profissionais pertencentes à Educação Infantil e outros Municípios e Região Metropolitana e entraram em contato com os pesquisadores solicitando participação. $O$ curso foi aberto a esses profissionais, desde que trabalhassem na Educação Infantil. Os que se interessaram em participar da pesquisa: 1) acessaram o link eletrônico (disponível no corpo do e-mail de convite) que direcionava a um formulário online para que o participante efetue a leitura e o aceite do Termo de Consentimento Livre e Esclarecido (TCLE); 2) o participante iniciava o preenchimento do questionário disponível, "Questionário das Concepções dos Profissionais da Educação sobre Intervenção Precoce", e 3) Acesso ao curso, em plataforma online, de "Intervenção Precoce na Educação Infantil" fornecido somente aos participantes que efetuaram o preenchimento completo do questionário, pois ao final do formulário foi disponibilizado um link eletrônico para que o participante fosse direcionado e tivesse acesso ao curso. Ao final do curso foi fornecida certificação pela Universidade na qual a pesquisa foi desenvolvida.

\subsection{Análise dos dados}

Para a análise quantitativa dos dados coletados online foi utilizado o pacote estatístico Statistic Package Social for Science (SPSS) na versão 21.0 em português para os sistemas operacionais Windows. Foi realizada análise estatística descritiva por meio de frequência, percentual, média, moda, mediada e desvio padrão dos dados.

Para a estatística inferencial, realizou-se o teste de Kolmogorov-Smirnov para averiguar se a distribuição dos dados era normal, comprovando-se que estatísticas paramétricas poderiam ser utilizadas. Para a análise de correlação foi utilizado o método de correlação 
de Pearson, com duas extremidades, e para a realização de testes de comparação de médias, o teste $t$ foi utilizado na comparação de pares e a análise de multivariância (ANOVA) com diversas variáveis independentes. Também foi feito o teste de confiabilidade $\alpha$ de Cronbach, com a finalidade de averiguar a consistência interna dos itens do questionário para a população da amostra. O nível de significância adotado foi de 0,05 .

\section{CONSIDERAÇÕES ÉTICAS}

A pesquisa foi enviada para avaliação ao Comitê de Ética Pesquisa com Humanos a fim de autorização, cedida com o número 1573473.

\section{RESULTADOS}

Os resultados fornecem um panorama sobre o perfil sociodemográfico dos profissionais da Educação Infantil, sua formação acadêmica e funções exercidas. Evidenciam os atrasos no desenvolvimento infantil mais frequentes observados por esses profissionais, bem como suas concepções sobre Intervenção Precoce, os profissionais e contextos envolvidos nesse processo, em especial o contexto familiar.

Os profissionais participantes desta pesquisa atuam na Educação Infantil e 75,8\% exercem a função de professores, $7,5 \%$ são diretores, $4,7 \%$ pedagogos, $4,3 \%$ estagiários, $3,7 \%$ agentes administrativos e $2,5 \%$ atuam como profissionais de apoio. Os demais profissionais, que atam como psicólogos e fisioterapeutas tiveram percentual inferior a 1\%. Desses profissionais, $74,2 \%$ atuam nos Centros Municipais de Educação Infantil da Prefeitura Municipal de Curitiba, 9,5\% em escolas municipais, 4,9\% em escolas particulares e escolas de educação básica na modalidade especial, 2,8\% em Centros de Educação Infantil particulares e 1,8\% atua nos Núcleos Regionais de Educação ou na Secretaria de Educação. Em relação ao turno de trabalho e carga horária semanal, $82 \%$ atuam em período integral, $64,5 \%$ de 30 a 40 horas e $18,3 \%$ trabalham entre 40 a 60 horas semanais. Esses profissionais encontram-se em média há mais de 5 anos na função atual e $84,7 \%$ sentem-se realizados com o trabalho, porém $44,7 \%$ já pensaram alguma vez em desistir da profissão.

A formação acadêmica é bastante variada: $63,7 \%$ são formados em Pedagogia, 1,9\% em Psicologia e Administração, 1,5\% em Letras e História, entre outros dez cursos de nível superior mencionados, cuja porcentagem foi inferior a $1 \%$. Uma porcentagem significativa desses profissionais, $25,5 \%$, possuem apenas o ensino médio, 20,8\% possuem uma segunda graduação, $37,6 \%$ apresenta pós-graduação. Os cursos de especialização 
que mais constaram foram Educação Infantil, Educação Especial/Inclusão, Psicopedagogia e Neuropsicologia.

Com relação a atuação profissional com crianças que apresentam atraso no desenvolvimento ou alguma deficiência, 39,6\% trabalham atualmente, $44,8 \%$ já trabalharam, $7,0 \%$ nunca trabalharam e $6,4 \%$ nunca trabalharam e no momento atuam na Secretaria Municipal ou Núcleos Regionais da Educação.

Os atrasos no desenvolvimento mais frequentes com os quais esses profissionais tiveram contato direto na El dizem respeito ao comportamento, à linguagem e ao desenvolvimento cognitivo, com a frequência de $51,2 \%, 40,6 \%$ e $30,3 \%$ respectivamente. E os atrasos que apresentam menor frequência são o atraso motor $(22,5 \%)$, visual $(17,5 \%)$ e auditivo (13,5\%). Entre os participantes da pesquisa, $24,4 \%$ afirmaram não saber o que é Intervenção Precoce. Os que apresentaram mais concepções verdadeiras sobre a relação à IP foram fisioterapeutas $(10,00)$, psicólogos $(8,33)$ e pedagogos $(6,93)$. Os que menos apresentaram foram os inspetores e estagiários. Dos profissionais participantes, $58,5 \%$ consideram a IP importante para o desenvolvimento da criança, 16,8\% que é exclusivamente para crianças com deficiência, $68,3 \%$ acreditam que a IP pode influenciar positivamente o curso do desenvolvimento, 32,3\%, acreditam que a IP constitui-se de atendimentos especializados direcionados à criança, $36,6 \%$ não acreditam que é só para a criança com deficiência, 39,3\% veem como ações integradas com diferentes contextos, $22,6 \%$ que são exercícios especializados orientados aos pais, $41,2 \%$ que exerce um fator de proteção ao desenvolvimento, 31,7\% consideram que a aprendizagem na IP pode acontecer no contexto natural da criança e 32,9\% pensam ser uma ação de responsabilidade pública.

O teste verificou que a correlação entre Concepções Verdadeiras e Como Identificam Atrasos no Desenvolvimento foi significativamente positiva, de $(r=0,180 ; p<0,01)$. No entanto, não foi encontrada correlação significativa entre Concepções Verdadeiras e Como Identificam Atrasos no Desenvolvimento $(r=0,78 ; p<0,05)$. Dessa forma, a hipótese levantada foi corroborada, pois, conforme visto, quem tem concepções verdadeiras sabe o que é Intervenção Precoce e esses participantes identificaram mais concepções verdadeiras no questionário aplicado. Observou-se também que as variáveis "Não saber o que é Intervenção Precoce" e "Identificar crianças que têm atraso no desenvolvimento" apresentaram uma correlação negativa significativa de $(r=-0,260 ; p<0,005)$, apontando que aqueles que não sabem definir Intervenção Precoce também identificam menos crianças que têm atraso no desenvolvimento. Quem atua na educação especial não apresenta necessariamente melhor compreensão a respeito de IP do que os profissionais do ensino comum, pois não foi encontrada correlação significativa. 
Em relação à família, os participantes sentem dificuldades no que se refere à comunicação $(37 \%)$, à presença da família em reuniões ou diálogos via agenda, $29 \%$, mencionam também a aceitação, no sentido de negarem a existência de algo fora do padrão normal de desenvolvimento: $17 \%$ citam a dificuldade da família em aceitar ou repassar para a unidade de ensino ou para a equipe de saúde os encaminhamentos médicos, o que é relatado pela unidade escolar.

Foi investigada a forma como os profissionais percebem o envolvimento das famílias das crianças com atraso no desenvolvimento sob diferentes aspectos. O primeiro aspecto foi em relação ao brincar com a criança: $52,90 \%$ dos profissionais acreditam que a família brinca às vezes com a criança e $21,00 \%$ acreditam que a família nunca ou quase nunca brinca com a criança. Constata-se a presença de uma visão positiva em relação à interação da família com a criança. Em relação ao diálogo da família com os profissionais da Educação Infantil, $52,9 \%$ dos profissionais dizem que as famílias os procuram às vezes para conversar sobre a criança e $22,5 \%$ nunca os procuram para conversar sobre os filhos com atraso no desenvolvimento. Os profissionais observam que, em relação ao interesse das famílias em saber sobre a aprendizagem dos filhos, $54,7 \%$ às vezes se interessam por sua aprendizagem, $25,4 \%$ quase sempre e sempre e $20 \%$ nunca e quase nunca se interessa pela aprendizagem dos filhos. Portanto, a grande maioria dos profissionais concebem as famílias como interessadas no desenvolvimento dos filhos.

Em relação ao comparecimento das famílias em reuniões nos Centros de Educação Infantil, 43,2\% mencionaram que as famílias às vezes comparecem em reuniões, $26,8 \%$ sempre e quase sempre e $27,2 \%$ disseram que as famílias nunca ou quase nunca comparecem nas reuniões.

A grande maioria dos profissionais concebem as famílias como interessadas no desenvolvimento dos filhos. Em relação ao comparecimento das famílias em reuniões nos Centros de Educação Infantil, 43,2\% mencionaram que às vezes comparecem em reuniões, $26,8 \%$ sempre e quase sempre e $27,2 \%$ disseram que as famílias nunca ou quase nunca comparecem nas reuniões.

No que se refere às concepções sobre Intervenção Precoce, observou-se correlação positiva significativa entre não ter conhecimento sobre IP e a Percepção sobre as famílias nos seguintes itens: 4.6.1 $=0,206^{* *}$; (Brinca com a criança) - quanto mais concepções falsas o profissional tem, mais acredita que a família brinca com a criança; 4.6.2 $=0,185^{\star *}$; (Procura conversar com você professor sobre as necessidades do filho) quanto mais concepções falsas o profissional tem, mais acredita que a família procura conversar com o profissional sobre as necessidades do filho; $4.6 .4=0,164^{* *}$; (Comparece às reuniões 
da Unidade/ escola) - quanto mais concepções falsas o profissional apresenta, maior a percepção de que as famílias comparecem às reuniões da unidade/escola com mais frequência. Todas essas correlações foram significativas $(p<0,05)$.

$\mathrm{Na}$ investigação da concepção sobre IP, foi observada uma correlação negativa significativa e moderada $(r=-0,530 ; p<0,05)$ entre ter concepções positivas e declarar não saber o que é Intervenção Precoce, quanto mais concepções verdadeiras os participantes declaram ter, menos eles declaram não saber o que é Intervenção Precoce, indicando que realmente dominam o conceito conforme a abordagem apresentada.

Os participantes que evidenciaram concepções falsas apresentaram correlação positiva significativa em relação ao envolvimento das famílias das crianças com atraso no desenvolvimento em relação a brincar com a criança $(r=0,206 ; p<0,05)$, procurar conversar com o professor sobre as necessidades dos filhos $(r=0,185 ; p<0,05)$ e comparecer às reuniões da Unidade $(r=0,164 ; p<0,05)$. Isso demonstra que, quanto maior o nível de concepções falsas, mais percebem o envolvimento das famílias das crianças com atraso em relação ao brincar, a procurar conversar com o professor sobre as necessidades dos filhos e comparecer às reuniões da unidade. Esses dados podem ser um indicativo de que ter concepções falsas está ligado às altas expectativas do profissional sobre a família. Isso pode levar a frustração decorrente dos baixos resultados do trabalho sem parceria efetiva. Essa variável também poderia explicar o alto índice de profissionais que, apesar de declararem gostar da profissão, também já pensaram em abandoná-la.

Outro dado constatado foi uma correlação positiva forte $(r=0,734 ; p<0,05)$ entre a percepção de que a família que procura mais o professor para conversar, também busca saber mais sobre o desenvolvimento e aprendizagem do filho.

Na compreensão dos profissionais da Educação Infantil, a família nuclear $(99,1 \%)$ e a família extensa $(71,9 \%)$ sempre ou quase sempre estão envolvidas no processo de IP. 0 professor é apontado como presente às vezes $(1,8 \%)$, quase sempre $(7,3 \%)$ e sempre em $90,9 \%$ dos casos. Os fisioterapeutas foram citados como nunca e quase nunca por $2,1 \% \mathrm{e}$ sempre e quase sempre por $68,6 \%$, psicólogos sempre e quase sempre em $82,3 \%$ e quase nunca em $0,9 \%$, assim como os fonoaudiólogos. A presença dos médicos foi apontada como sempre e quase sempre por $82,8 \%$ dos participantes e nunca e quase nunca em $2,4 \%$. A família, o professor e a escola foram os mais citados como importantes na Intervenção Precoce.

Dos profissionais que responderam ao questionário apenas fisioterapeutas e psicólogos disseram saber o que é IP; $100 \%$ dos inspetores, $35,7 \%$ dos estagiários, $25 \%$ dos 
profissionais de apoio e dos agentes administrativos e $24,6 \%$ dos professores de Educação Infantil e $12,5 \%$ dos diretores declararam não saber o que é Intervenção Precoce. Entre os pedagogos, apenas 6,7\% disseram não saber o que é IP.

A maioria dos participantes que disseram ter feito curso sobre IP apresentaram mais concepções verdadeiras, porém apenas $18 \%$ dos participantes declararam já ter feito curso. As concepções verdadeiras estão positivamente relacionadas ao fato de ter participado de cursos de IP. A significância encontrada foi de 0,001.

Do total dos participantes, 39,3\% disseram ver a IP como uma ação no contexto. Dos que não veem a IP como ação integrada entre diferentes contextos estão os agentes administrativos (66,7\%) e os professores de Educação Infantil (66\%). A grande maioria $(74,4 \%)$ acredita que a IP é só para crianças com deficiências. Quem mais acredita nisso são os professores da Educação Infantil (69,3\%), seguida dos agentes administrativos $(66,7 \%)$, estagiários $(64,3 \%)$ e $36,5 \%$ dos professores.

Entre os profissionais que não veem a IP como um fator de proteção para o desenvolvimento estão $63,7 \%$ dos professores e $63,5 \%$ dos profissionais de apoio. Dos profissionais que acreditam que a IP consiste em experiências do dia a dia proporcionadas à criança no contexto natural de aprendizagem estão $93,9 \%$ dos estagiários, $75 \%$ dos agentes administrativos e profissionais de apoio, e 31,1\% dos professores da Educação Infantil. Os estagiários (86,7\%), agentes administrativos (84,3\%) e 68\% dos professores da Educação Infantil não acreditam poder ser uma ação no contexto natural de aprendizagem.

\section{DISCUSSÃO}

A partir da análise das concepções levantadas verificou-se que poucos profissionais admitiram não saber o que é Intervenção Precoce, no entanto poucos revelaram concepções dentro dos modelos de IP reconhecidos como boas práticas pela literatura internacional. Os resultados mostram que quem declarou saber o que é Intervenção Precoce identifica mais e melhor as crianças que têm atraso ou deficiência. Essa identificação ocorre mais quando há atraso motor global, atraso na coordenação motora fina, dificuldade de interação com colegas e baixo nível de iniciativa da criança. Apesar de possuírem formação boa parte dos professores não conhecem as fases do desenvolvimento e não identificam sinais de atraso (VALIATTI, 2014).

Os dados da pesquisa mostram maior preocupação com o desenvolvimento motor. Isso talvez possa justificar os atrasos do desenvolvimento mais observados pelos participantes: comportamento, linguagem e desenvolvimento cognitivo. É provável que essa 
visão leve a maior ênfase de trabalho na área motora. Segundo Souza (2008) muito do conhecimento e da atuação dos professores é baseada na prática e na necessidade imediata, e essa ação empírica tende a associar o desenvolvimento ao aspecto motor, em detrimento de habilidades cognitivas e sociais, bem como considerar menos relevantes os aspectos ambientais.

As concepções apontadas sobre desenvolvimento não são compatíveis com o conhecimento gerado pela perspectiva bioecológica e pelo modelo transacional, onde o desenvolvimento não depende só do cuidado das relações diretas ou de processos intrapsíquicos, mas da influência das relações dos diferentes contextos que envolvem a pessoa e dos níveis de interação - dos mais próximos aos mais distantes (BRONFENBRENNER, 2011). Destacam-se alguns dados que evidenciam a distância dessa visão de desenvolvimento, quando participantes revelam suas concepções sobre IP: menos da metade a concebe como ações integradas com diferentes contextos. A maioria não acredita que exerce um fator de proteção ao desenvolvimento e poucos a veem como a possibilidade de aprendizagem no contexto natural. Grande parte dos participantes não concebe a IP como um fator de proteção para o desenvolvimento, e não a vem como possibilidade de antecipar problemas.

A Intervenção Precoce, segundo Franco (2015), tem como princípios olhar a criança como um todo, buscando apoio de serviços integrados e estar atenta ao contexto que envolve a criança e às prioridades para o seu desenvolvimento, seja terapêutico, educativo ou relacional, procurando potencializar as interações da família e cuidadores. Na abordagem de desenvolvimento de sistemas, a IP volta-se para três níveis de atenção relacionados: atenção ao desenvolvimento da criança; a identificação de influências ambientais e identificação dos recursos da família (GURALNICK, 2011).

A grande maioria dos participantes acredita que a IP se destina apenas a crianças com deficiência, principalmente os professores. Isso mostra a forte presença do modelo médico, que concebe a IP como programas terapêuticos voltados à supressão de defasagens cujo foco principal é a criança (JERUSALINSKY, 1994, CORIAT, 1997, FRANCO, 2015). Por outro lado, uma contradição fica evidente quando diretores, profissionais de apoio e estagiários respondem que fisioterapeutas, fonoaudiólogos e psicólogos quase nunca estão envolvidos na IP; e a grande maioria considera como participantes da IP a família nuclear, a escola e o professor. Esse quadro retrata a presença de duas concepções extremas, a médico-clínica e a de senso comum, que remete a um não saber científico sobre os aspectos que envolvem o desenvolvimento e a IP.

Os profissionais que atuam na educação especial não evidenciaram melhor compreensão a respeito da IP se comparados aos que atuam no ensino comum. A experiência 
não teve prevalência, reforçando a ideia de que a formação continuada pode gerar mudanças de concepção. Há casos em que o professor resiste a mudar porque obteve sucesso pensando e agindo de determinada forma. Isso daria certo se escola, sociedade e aluno fossem estáticos, porém, estão em permanente mudança, não se obtém resultados diferentes agindo da mesma forma sobre um contexto em permanente mudança. (MINETTO, 2008).

Os papéis dos CMEls e das famílias confundem-se para os professores, pois o próprio conceito de educação se dissolve na tentativa de definir atribuições de um e de outro. A maternidade e a vocação ainda são colocadas como requisitos para ser professor na Educação Infantil, o que desvaloriza a importância da formação, e gera um profissional acrítico com dificuldades para potencializar as circunstâncias postas à prática e sem consciência das intencionalidades que devem presidi-las. (FRANCO, 2016; GUIMARÃES, ARENHART, SANTOS, 2017).

A maioria dos participantes que fizeram curso sobre IP apresentam mais concepções verdadeiras, ou seja, aproximaram-se mais do que é considerado boa prática pela literatura internacional; o que corrobora a importância de cursos de formação. A falta de formação dificulta que os professores compreendam melhor sua função e possam exercer um trabaIho voltado à promoção do desenvolvimento e não apenas ao cuidado diário, um trabalho diluído nas exigências da prática. Isso gera uma característica dos professores da Educação Infantil, apontada em muitas pesquisas: a da desvalorização do próprio trabalho, pois subestimam sua função na promoção do desenvolvimento das crianças. (FRANCO, 2016; HADDAD, CORDEIRO, CORREIA, 2015).

Os participantes que disseram não ter conhecimento sobre IP têm a concepção de que a família está mais presente e participativa no ambiente escolar. Ao comparar esses participantes aos que afirmaram saber o que é IP, verificou-se que, quanto mais concepções falsas, mais positiva e fantasiosa a visão sobre a participação e envolvimento da família. Isso pode ser um indicativo da idealização por parte desses profissionais de que os pais estão presentes e cumprindo com seus deveres para com os filhos, o que pode não estar ocorrendo. A avaliação equivocada do contexto e da presença familiar pode não evocar ações assertivas. A provável consequência disso são as frustrações no trabalho, uma vez que aumenta a probabilidade de resultados negativos (WITTER, 2003).

Outro dado constatado foi uma correlação positiva entre a concepção de que a família que procura mais o professor para conversar, busca também saber mais sobre o desenvolvimento e aprendizagem do filho. A atenção ao contexto familiar traz inúmeros ganhos ao desenvolvimento, pois, na perspectiva bioecológica, a intervenção não precisa ser feita 
diretamente sobre a criança e talvez nem mesmo sobre a mãe ou a família. Essa perspectiva amplia a visão no sentido de colocar a influência de outros fatores sobre o desenvolvimento. Portanto, pode-se obter ganhos ao intervir sobre qualquer um dos ambientes de desenvolvimento (FRANCO, 2015).

É importante salientar que não cabe ao CMEl/Educação Infantil fazer o trabalho de um programa de Intervenção Precoce, mas sim ter a visão de que todos os contextos, assim como ele próprio, têm importância para o desenvolvimento da criança.

A necessidade de maior conhecimento sobre os aspectos que envolvem o desenvolvimento e a Intervenção Precoce ficam evidentes quando apenas 15,5\% dos participantes entendem a IP como promotora de confiança e competência nos adultos responsáveis e a maioria dos professores não a consideram um fator de proteção para o desenvolvimento. A família, como observam Carvalho et al. (2016) e Minetto, Crepaldi e Bermudez (2017), possui um papel fundamental na implementação das práticas de IP. Uma vez que permanecem por mais tempo em contato com as crianças, seu empoderamento é imprescindível para que utilizem ao máximo seu potencial a favor do desenvolvimento da criança (DUNST, HAWKS, 1015).

Nota-se uma distância na comunicação família-escola, o professor pouco amparado e sobrecarregado em sua rotina profissional, muitas vezes atrelado à uma prática irreflexiva, o que resulta no empobrecimento da capacidade de leitura e significação das necessidades de sala de aula, e o consequente insucesso, frustração profissional e impossibilidade de otimização do desenvolvimento e aprendizagem da criança.

Trabalhar com a primeira infância requer a priori conhecer profundamente os aspectos que geram o desenvolvimento e estar atento à necessidade de inserção de crianças com atraso no desenvolvimento ou com deficiência em programas de intervenção precoce. Fica evidente a diversidade de concepções concernentes à IP, a pouca literatura na área e a necessidade de atualização dos profissionais da Educação Infantil para que a importância da IP seja disseminada no ambiente educacional.

\section{REFERÊNCIAS}

ALEIXO, Elisabete Pereira Lopes. Práticas de intervenção precoce centradas nos contextos naturais e o seu contributo para a promoção do desenvolvimento da criança. Dissertação de mestrado. Instituto Politécnico de Coimbra, 2014. 
BRASIL. Ministério da Educação. Secretaria da Educação Lei n 9.394 . Estabelece as diretrizes e bases da educação nacional, 1996. Disponível em: <http://goo.gl/3ClalE>, acesso em 02 de julho de 2018.

BRASIL. Ministério da Educação. Secretaria de Articulação com os Sistemas de Ensino (MEC/SASE). Conhecendo as 20 metas do Plano Nacional de Educação, 2014. Disponível em: <http://goo.gl/E9HmLE>, acesso em 02 de julho de 2018.

BRONFENBRENNER, Uri. Bioecologia do desenvolvimento humano: tornando os seres humanos mais humanos. Tradução de Carvalho-Barreto. Porto Alegre: Artes Médicas, 2011.

CARVALHO, Elisa. Apostila modelo e conceito de Intervenção Precoce. Universidade Portucalense, Porto, 2008.

CORIAT, Elsa. Psicanálise e clínica de bebês. Porto Alegre: Artes e Ofícios, 1997.

COSTA, Regina Célia Gradowski Faria da. O estado do conhecimento sobre estimulação precoce no conjunto de teses e dissertações brasileiras no período entre $2000 \mathrm{e}$ 2011. Dissertação de mestrado: Universidade Federal do Paraná. Curitiba, Paraná, 2012.

DORNELAS, Lilian de Fatima; DUARTE, Neuza Maria; MAGALHÃES, Livia de Castro. Atraso do desenvolvimento psicomotor: mapa conceitual, definições, usos e limitações do termo. Revista Paulista de Pediatria, p. 88-103, 2015. Disponível em: <http://www.scielo. br/pdf/rpp/v33n1/pt_0103-0582-rpp-33-01-00088.pdf>, acesso em 02 de julho de 2018.

DUNST, Carl; HAWKS, Orelena. Family-centered practices: birth through High School Puckett Institute. The Journal of Special Education. Asheville, North Carolina, p. 139-147, 2015. Disponível em <http://goo.gl/2GexS7>, acesso em 02 de julho de 2018.

FERNANDES, Patrícia Raquel Silva. Diálogos sobre a Intervenção precoce em Portugal e no Brasil: Classificação nacional e internacional sobre práticas profissionais. Tese de doutorado em estudos da criança: Universidade do Minho, 2016.

FORMIGA, Cibelle; VIEIRA, Martina; LINHARES, Maria Beatriz. Avaliação do desenvolvimento de bebês nascidos pré-termo: a comparação entre idades cronológica e corrigida. Revista Brasileira de Crescimento e Desenvolvimento Humano: São Paulo, v. 25, n.2, 2015. Disponível em: <http://goo.gl/RGspkT>, acesso em 02 de julho de 2018.

FRANCO, Maria Amélia de Rosario Santoro. Prática pedagógica e docência: um olhar a partir da epistemologia do conceito II. Revista Brasileira de Estudos Pedagógicos, Brasília, v.97, n.247, p. 534-551, 2016. Disponível em: <http://dx.doi.org/10.1590/S21766681/288236353>, acesso em 02 de julho de 2018. 
FRANCO, Vitor. Contributos Psicodinâmicos para a intervenção precoce na infância. Évora: Edições Aloendro, 2016.

FRANCO, Vitor. Introdução à Intervenção Precoce no desenvolvimento da criança: com a família, com a comunidade, em equipe. Évora: Edições Aloendro, 2015.

FRANCO, Vitor; APOLÓNIO, Ana. Avaliação diagnóstica em Intervenção Precoce. In: INFAD, 2011. Évora, 2011.

FRANCO, Vitor; MELO, Madalena; APOLONIO, Ana. Problemas do desenvolvimento infantil. Educar em Revista: Curitiba, p. 49-64, 2012. Disponível em: <http://goo.gl/cDAPPw>, acesso em 02 de julho de 2018.

GAT. ODAT Descritivo Manual-Update 2008. Madrid: Royal Board on Disability, 2008. Disponível em: <http://goo.gl/O2xMpq>, acesso em 02 de julho de 2008.

GUIMARÃES, Daniela; ARENHART, Deise; SANTOS, Nubia. Educação Infantil Pós LDB/1996: Formação inicial de professores e práticas pedagógicas. Revista Contemporânea de Educação, Rio de Janeiro, v.12, n.24, 2017. Disponível em: <https://revistas.ufrj.br/ index.php/rce/article/view/4171/pdf_1>, acesso em 02 de julho de 2018.

GUIMARÃES, Henrique Manuel. Concepções, crenças e conhecimento: afinidades e distinções essenciais. Instituto de Educação: Universidade de Lisboa Quadrante, v.19, n.2, 2010. Disponível em: <http://repositorio.ul.pt/bitstream/10451/11019/1/ConcepCrenConhec_Quadrante_pp81-102.pdf>, acesso 02 de julho de 2018.

GURALNICK, Michael. Early Intervention for Children with Intellectual Disabilities: An Update. Journal of Applied Research Intellectual Disabilities, p.1-19, 2016. Disponível em: <https://onlinelibrary.wiley.com/doi/pdf/10.1111/jar.12233>, acesso em 02 de julho de 2018.

GURALNICK, Michael. Merging Policy Initiatives and Developmental Perspectives in Early Intervention. Escritos de Psicologia, Washington, v.8, p.6-13, 2015. Disponível em: <https://www.ncbi.nlm.nih.gov/pmc/articles/PMC4747327/pdf/nihms722127.pdf>, acesso em 02 de julho de 2018.

GURALNICK, Michael. Why early intervention works: a systems perspective. Infants \& Young Children, v. 24, p. 6-28, 2011. Disponível em: <https://insights.ovid.com/crossref?an=00001163-201101000-00002>, acesso em 02 de julho de 2018.

HADDAD, Lenira; CORDEIRO, Maria Helena; CORREIA Maysa. Competências esperadas do professor e o brincar na educação infantil: reflexões a partir da técnica de substituição. Revista Educação e Cultura Contemporânea, v.12, n.29, 2015. Disponível em: <http:// 
revistaadmmade.estacio.br/index.php/reeduc/article/view/861/764>, acesso em 02 de julho de 2018.

JERUSALINSKY, Alfredo. Psicanálise e desenvolvimento infantil. Letra Psicanalítica, Porto Alegre, 1994.

KARANEZI, Xhevahire; RAPTI, Edmond. Teachers Attitudes and perceptions: association of teachers' attitudes toward traditional and modern teaching methodology according to RWCT as well as teachers' perceptions for teaching as a profession. Creative Education, v.6, n.6, 2015. Disponível em: <http://dx.doi.org/10.4236/ce.2015.66061>, acesso em 02 de julho de 2018.

MARINI, Bruna. LOURENÇO, Mariane, BARBA, Patrícia. Revisão sistemática integrativa da literatura sobre modelos e práticas de intervenção precoce no Brasil. Revista Paulista de Pediatria: São Paulo, 2017. Disponível em: <http://www.scielo.br/pdf/rpp/v35n4/ 0103-0582-rpp-2017-35-4-00015.pdf>, acesso em 02 de julho de 2018.

MATOS, Daniel; JARDILINO, José Rubens. Os Conceitos de Concepção, Percepção, Representação e Crença no Campo Educacional: Similaridades, Diferenças e Implicações para a Pesquisa. Revista Educação \& Formação: Fortaleza, v.1, n.3, p. 20-31, 2016.

MINETTO, Maria de Fatima. Currículo na educação inclusiva: entendendo esse desafio. 2 ed. Curitiba: IBEPEX, 2008.

MINETTO, Maria de Fatima. Práticas educativas parentais, concepções parentais, estresse parental e funcionamento familiar de pais de crianças com desenvolvimento típico e atípico. (Tese de doutorado). Universidade Federal de Santa Catarina. 2010. Recuperado de https://goo.gl/eDdtl7.

MINETTO, Maria de Fatima; CREPALDI, Maria Aparecida. Visão bioecológica do desenvolvimento humano. In: Minetto, Maria de Fatima; Bermudez, Beatriz. Bioecologia do desenvolvimento humano na síndrome de Down: práticas em saúde e educação baseada em evidências. Acompanhamento interdisciplinar. Curitiba: Ithala, p.39-52, 2017.

MINETTO, Maria de Fatima; CREPALDI, Maria Aparecida; BERMUDEZ, Beatriz. Prontuário Bioecológico para o atendimento da pessoa com Síndrome de Down. In: Minetto, Maria de Fatima; Bermudez, Beatriz. Bioecologia do desenvolvimento humano na síndrome de Down: práticas em saúde e educação baseada em evidências. Acompanhamento interdisciplinar. Curitiba: Ithala. p. 277-286, 2017.

PEREZ E RAMOS, A. M. Modelos de intervenção: perspectivas dos programas de estimulação precoce. Psicologia USP, 67-75. 1990. Recuperado de http://goo.gl/spQpHG. 
SAMEROFF, Arnold. The transactional model of development: How children and contexts shape each other. Washington, D. C: American Psychological Association, 2009.

SAMEROFF, Arnold; OLSON, Sheryl. Familial risk and child competence. Institute for the Study of Developmental Disabilities. Society for Research in Child Development: University of Illinois at Chicago, 2011.

SAMEROFF, Arnold.J; CHANDLER, M.J. Reproductive risk and the continuum of caretaking casualty. In: Horovitz, F.D. et al. Review of child development research. Chicago: University of Chicago Press p.187-244, 1975.

SAMEROFF, A.J. \& FIESE, B.H. Transactional regulation: The developmental ecology in early intervention. In J.P. Shonkoff \& S.J. Meisels (Eds), Handbook of early intervention (2th ed., pp. 135-159). Cambridge: Cambridge University Press, 2000.

SAMPIERI, Roberto; COLLADO, Carlos; LUCIO, Maria. Metodologia de pesquisa. Porto Alegre: Penso, $5^{\circ}$ ed., 2013.

SANCHES-CARAVACA, Juan; GIL, Isidoro. Aplicação de programas de atenção precoce a partir de um modelo educativo. Educar em revista, Curitiba, n.43, p.33-48, 2012. Disponível em: <http://goo.gl/Zv5Wpc>, acesso em 02 de julho de 2018.

SERRANO, A. M. Redes sociais de apoio e a sua relevância para a intervenção precoce (Coleção Educação Especial, 110 p.). Porto: Porto Editora, 2007.

SOEJIMA, Carolina. Atenção e estimulação precoce relacionada ao desenvolvimento da criança de zero a três anos de idade no ambiente da creche. Tese de Doutorado: Curitiba, 2008. Disponível em: <http://goo.gl/WjwE6G>, acesso em 02 de julho de 2018.

SOUZA, Nelly Narcizo de. Concepções de educadoras de creche sobre o desenvolvimento da criança na faixa etária de zero a três anos. Dissertação de mestrado: Curitiba, 2008. Disponível em: <http://www.ppge.ufpr.br/teses/M08_souza.pdf>, acesso em 02 de julho de 2018.

UNESCO. Declaração Mundial sobre Educação para Todos: satisfação das necessidades básicas de aprendizagem Jomtien. 1990. Disponível em: <http://goo.gl/HrpNnB>, acesso em 02 de julho de 2018.

VALIATTI, Marcia Regina Machado Santos. Atraso no desenvolvimento neuropsicomotor: fatores de risco e intervenção precoce nos centros de educação infantil. Tese de doutorado: Universidade Federal do Paraná, Curitiba, Paraná, 2014. Disponível em: <https://acervodigital.ufpr.br/handle/1884/40385>, acesso em 02 de julho de 2018. 
WITTER, Geraldina Porto. Professor-estresse: análise de produção científica. Revista psicologia escolar e educacional: Campinas, v.7, n.1, p.33-46, 2003. 